\title{
Development of a software algorithm working with infrared images and useful for the early detection of mastitis in dairy cows
}

\author{
by M. Zaninelli*, V. Redaelli**, F. Luzi" ${ }^{* *}$ V. Bronzo**, A. Tappella** M. Mitchell ${ }^{* * *}$, V. Dell'Orto ${ }^{* * * *}$ \\ D. Cattaneo ${ }^{\star \star \star *}$, G. Savoini ${ }^{\star \star \star \star}$ \\ * Department of Human Sciences and Quality of Life Promotion, Università Telematica San Raffaele Roma, Via \\ di Val Cannuta 247, Rome 00166, Italy, mauro.zaninelli@unisanraffaele.gov.it \\ ** Department of Veterinary Medicine, Università degli Studi di Milano, Via Celoria 10, Milan 20133, Italy; \\ veronica.redaelli@unimi.it, fabio.luzi@unimi.it,valerio.bronzo@unimi.it \\ ${ }^{* * *}$ Animal \& Veterinary Sciences, Scotland's Rural College, Roslin Institute Building, Easter Bush, Midlothian, \\ Scotland, UK; malcolm.mitchell@sruc.ac.uk; \\ **** Department of Health, Animal Science and Food Safety (VESPA), Università degli Studi di Milano, Via \\ Celoria 10, Milan 20133, Italy; vittorio.dellorto@unimi.i; valentino.bontempo@unimi.it; \\ donata.cattaneo@unimi.it; giovanni.savoini@unimi.it
}

\begin{abstract}
A clinical mastitis could increase the animal' basal temperature and change the blood circulation at tissue level, causing an increase of the udder surface skin temperature (USST) that can be detected by infrared camera. In this study a first field test was carried out acquiring thermografic images from different dairy farms. Furthermore, a dedicated software algorithm was developed and tested to evaluate thermografic images acquired and to calculate specific infrared parameters. The results have shown that the parameter USST could be related to the healthy states of cow udder and to the imaging elaboration. Futhermore, the thermografic parameters tested in this first field investigation showed to be a possible useful tool in the development of an effectiveness monitoring systems based on the use of infrared technology.
\end{abstract}

\section{Introduction}

Nowadays, mastitis is the most frequent disease that affects animal's health and farm production [1]. Its early detection remains a goal to improve the farm efficiency [2, 3]. Many parameters have been considered in order to reach this target. Some of these, are laboratory analysis not applicable at farm level such as the somatic cell count (SCC) and the bacteriological examination (BAC) of milk samples [4]. Others, are indicators that can be considered at farm such as the electrical conductivity (EC) of milk [5]. Nevertheless, their accuracy in the detection of unhealthy states of the mammary gland are not always enough for an efficient monitoring of udder health status [6]. Thus, new parameters and/or devices are still necessary.

When a dairy cow has a mastitis, some clinical signs can be recorded. Since a mastitis is always related to a local inflammation, an increase of the udder surface skin temperature (USST) and/or a greater animal' basal temperature can be observed and detected without any contact by infrared thermography (IRT) [7-9].

With this objective, some investigations have been performed by some authors finding positive results. For example, Scott et al. (2000) [10] have found that quarters artificially infected by E. coli lipopolysaccharide (LPS) show, in the following six hours after the infection, a greater USST of $2.3^{\circ} \mathrm{C}$. Hovinen et al. (2008) [6], in a test that involved six cows, have demonstrated that an increase of 1 to $1.5^{\circ} \mathrm{C}$ can be detected by the use of IRT in quarters with a clinical mastitis artificially induced. Metzner et al. (2015) [11], in a test on five cows experimentally exposed to E. coli, have showed that IRT was able to detect a mastitis when maximum temperatures values $\left(T_{\max }\right)$ of one or both headquarters, were considered with a sampling interval of less than two hours. However, the above cited researches were carried out on few animals or experimental cases. Furthermore, different experimental designs were adopted in terms of: udder quarters considered, udder surfaces investigated, temperature parameters evaluated ( $T_{\max }$, average temperature, difference between udder quarters, etc.), ambient parameters and definitions of the udder gland status (SCC, California Mastitis Test, etc.). As a consequence, further investigations on the effectiveness of the IRT for the measuring of the USST and the monitoring of the cow udder health status are still necessary. Furthermore, dedicated software algorithm for the image elaboration should be tested to improve the standardization and the automation of the measurements and procedures. With this aim, this study was carried out. 


\section{Material and methods}

\subsection{Animals and farms}

The study was carried out form July 2016 to January 2018. It involved dairy cows reared in four different medium size farms located in the North of Italy. In detail, the experimental group of animals was composed by: 80 Holstein Friesian cows, from farm 1; 68 Holstein Friesian cows, from farm 2; 74 Holstein Friesian cows, from farm 3; and 70 Holstein Friesian cows, from farm 4. Each cow did not have any clinical sign of mastitis. Stage of lactation was different for each cow and ranged between 15 to 275 days. Cows were feed twice a day with a total mixed ration according to their state of lactation. They were housed in free-stalls with straw beddings changed 2 or 3 times per week. Cows were milked by automatic milking systems (AMS) or by conventional milking systems of different manufactures, sizes and layouts.

\subsection{Milk sampling, milk sample analysis and definition of udder health status}

Milk samples were collected during milking procedures. Each cow was examined in order to avoid a possible case of clinical infection visible at udder level and/or by physical changes of milk. From each cow, a composite milk sample was automatically collected. At the end of the day of sampling, a technician of Local Breeders Association, within Dairy Herd Improvement Program (DHI), collected all milk samples of the analyzed farm and processed them for SCC in the following day of sampling, following the international recommendations [12].

In accordance with experimental designs already followed in previous tests [7], SCC results were considered to classify the health status of udders and the thermographic indicators investigated in this study. A cut-off of $200,000 \mathrm{cells} / \mathrm{mL}$ was taken into consideration in order to discriminate healthy and unhealthy cases.

\subsection{Thermografic images collection}

Thermografic images were collected during milking procedures using a commercial infrared camera (Thermo GEAR-G120 - Nippon Avionics Co, Tokyo, Japan). It had an uncooled detector (microbolometer) with a $320 \times 240$ pixels focal plane array. Its accuracy was $\pm 2{ }^{\circ} \mathrm{C}$ with a sensitivity of $0.04{ }^{\circ} \mathrm{C}$ (at $30^{\circ} \mathrm{C}$ ). Before to acquire each thermografic image, the IRT camera was set up in order to take into account the milking parlour temperature (that ranged during the whole experimental period from 16 to $27^{\circ} \mathrm{C}$ ) and the internal calibration feature was used. Emissivity value was set at 0.98 to complete the settings of the camera. Thermografic images were acquired during milking procedures, positioning the infrared camera at udder level, at a distance of circa 0.5 from the lateral part of each udder (figure 1-A). Previous researches have shown that milking procedures should not affect the measurement of USST [13].

All acquired images were analyzed by a dedicated software application developed in LabVIEW (National Instruments, Austin, TX, USA - version: 8.5) using also some specific subroutines of the Vision Acquisition Software (NI version: 2009) and Vision Development Module ( $\mathrm{NI}$ - version: 2009). The software application was able to work off-line on a set of ".bpm" files formatted with a gray-level scale and a resolution of 8 bit. On each image file, the software algorithm performed the following tasks in automatic:

- $\quad$ it identified the pixel with the maximum intensity ( $\mathrm{PI}_{\max }$, figure 1-C), calculating its coordinates inside the image and its value (related to the maximum recorded temperature in the thermografic image).

- It calculated a range of intensities to use as thresholds, in order to detect the udder of the cow, (figure 1-B) according to the following formulas:

$$
\begin{aligned}
& \text { Upper value }=P I_{\max } \\
& \text { Lower } \text { value }=0.8 \times P I_{\max }
\end{aligned}
$$

- On the filtered image, it applied a grid made by image subsections of $16 \times 16$ pixels.

- On each image subsection, it calculated the pixel average intensity (i.e. the recorded average temperature of the image subsection evaluated).

- $\quad$ On the resulting set of pixel average intensities, it selected the maximum value and it considered that number as the recorded maximum temperature of the thermografic image evaluated (i.e. the $T_{\max }$ ), taken as possible indicator of the udder health state in accordance with results of previous scientific researches [6, 11]).

- It calculated a "temperature proximity area" $\left(\mathrm{AP}_{\mathrm{T}}\right.$, figures 1-C and 1-D) considering the coordinates of $\mathrm{PI}_{\max }$ as a starting point and a set of connected pixels which intensities were different from zero after to have applied the following filter:

$$
P I_{\text {New }}=\left\{\begin{array}{cc}
0 & P I_{\text {old }}<P I_{\text {max }}-T \\
P I_{\text {old }} & P I_{\text {max }}-T \leq P I_{\text {old }} \leq P I_{\text {max }}
\end{array}\right.
$$

where the parameter $\mathrm{T}$ (tolerance) was set up at a level of 30 . Furthermore, a connectivity mode of 8 pixels was used for the recursive application of the above reported filter [14]. This value specified at the algorithm 
whether a pixel should be considered in the following cycle. In detail, it imposed at the software application to take into consideration all the 8 surrounding pixels of the pixel under evaluation for the filtering operations that followed.

After to have evaluated all acquired thermografic images, the software application reported the obtained results in a".txt" file in order to allow the performing of statistical analysis.
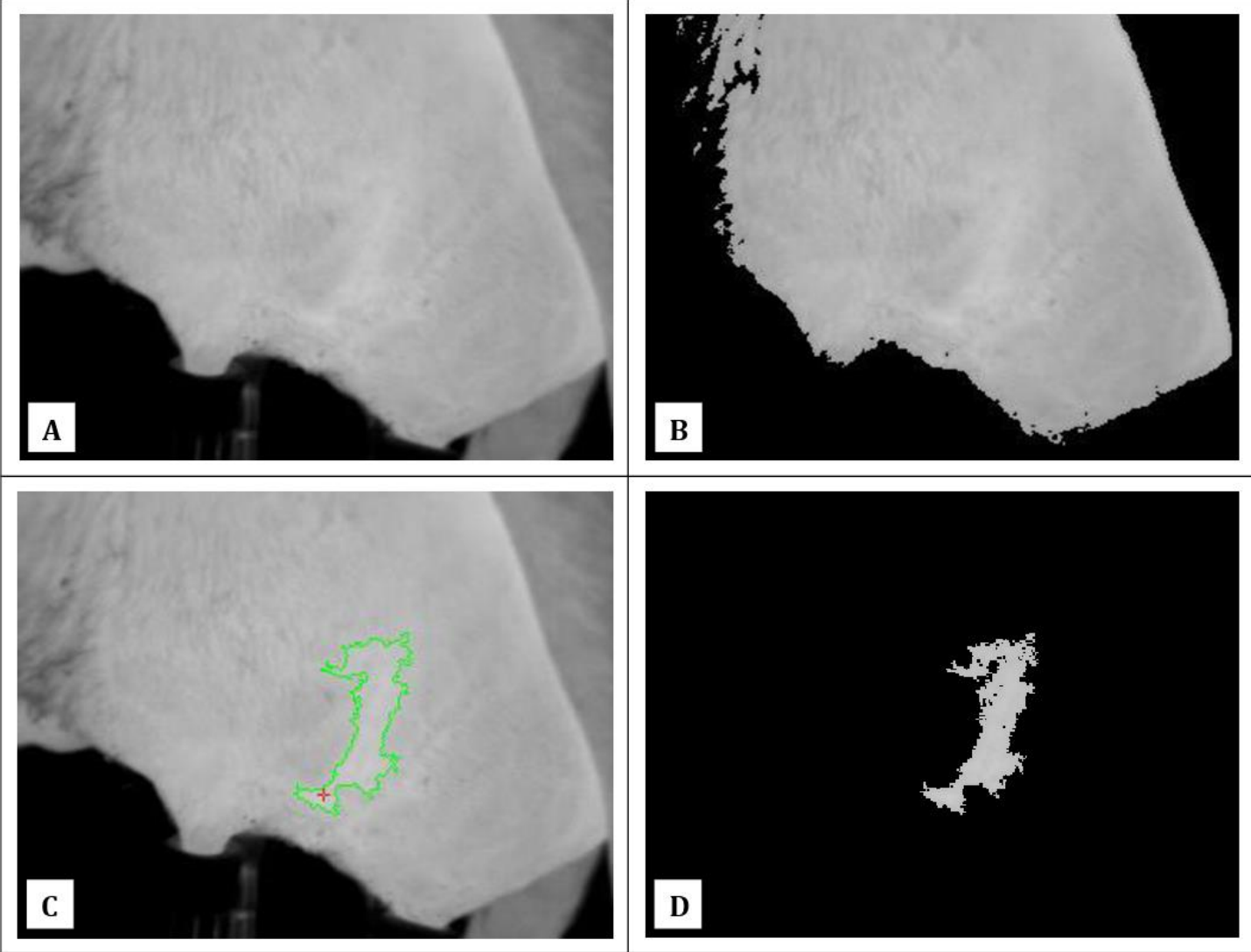

Fig. 1: The figure shows some image elaborations performed by the algorithm of the developed software application. In details, in $(A)$ is reported an example of a thermografic image acquired during the study carried out. In $(B)$ is shown the result obtained applying as thresholds, a range of intensities calculated through the above reported formulas (1-2) and after have identified in the thermografic image the pixel with the maximum intensity value $\left(P I_{\max }\right)$. In the figure, almost the whole cow udder is highlighted. As a consequence, a grid, of

dimensions $4 \times 4$ pixels can be applied in order to calculate the surface distribution of temperatures. In a

following step, the maximum value of udder skin temperature $\left(T_{\max }\right)$ can be identified as the maximum value within the surface temperatures calculated. In (D), is reported the "temperatures proximity area" $\left(A P_{T}\right)$ obtained considering the coordinates of $P I_{\text {max }}$ and a set of connected pixels which intensities are different from zero after to have applied the above reported filter (3). In (C), finally, it is shown with a red cross the location of the pixel $P I_{\text {max }}$ and with a green contour the $A P_{T}$ calculated.

\subsection{Statistical analysis}

Data obtained from image elaborations were investigated through statistical analysis performed using the "R" software tool (version 3.4.3, 2017) [15] and the ability of the parameter $T_{\max }$ to discriminate a possible case of mastitis was also investigated. When $T_{\max }$ overcame a settled threshold a case of mastitis was supposed (i.e. the result of a possible statistical test was set up as positive). On the basis of SCC on the corresponding milk sample, udder health status was defined (i.e. "healthy" if SCC was lower than a defined threshold or "unhealthy" if SCC was higher than the selected threshold) and compared with the results of statistical test. In this way the following classes were obtained: true positive (TP); false positive (FP); true negative (TN) and false negative (FN). When all results were classified, the performance of the statistical test based on evaluations of parameter $T_{\max }$ was calculated as sensitivity and specificity, in accordance with the following formulas: 


$$
\begin{aligned}
& \text { Sensitivity[\%] }=\frac{T P}{\mathrm{FN}+\mathrm{TP}} \\
& \text { Specificity }[\%]=\frac{\mathrm{TN}}{\mathrm{FP}+\mathrm{TN}}
\end{aligned}
$$

Of course, the statistical test gave different couples of sensitivity and specificity for each possible threshold used to evaluate the parameter $T_{\max }$. For this, a receiver operating characteristic $(R O C)$ curve was build using the procedures "prediction" and "performance" of the package "ROCR" (version 1.0.7). Analyzing the curve, a specific cutoff was selected and the corresponding couple of sensitivity and specificity was identified as final performance reached by the parameter $T_{\max }$ in the detection of a possible case of unhealthy cow udder. Furthermore, also the area under the curve (AUC) was considered to study the performance of the parameter $T_{\max }$.

\section{Results}

In the statistical analysis performed, the performance of the parameter $T_{\max }$ was evaluated and a ROC curve was calculated through the couples of sensitivity and specificity obtained by the statistical test when different possible cut-off levels were selected. The ROC curve calculated is reported in figure 2:

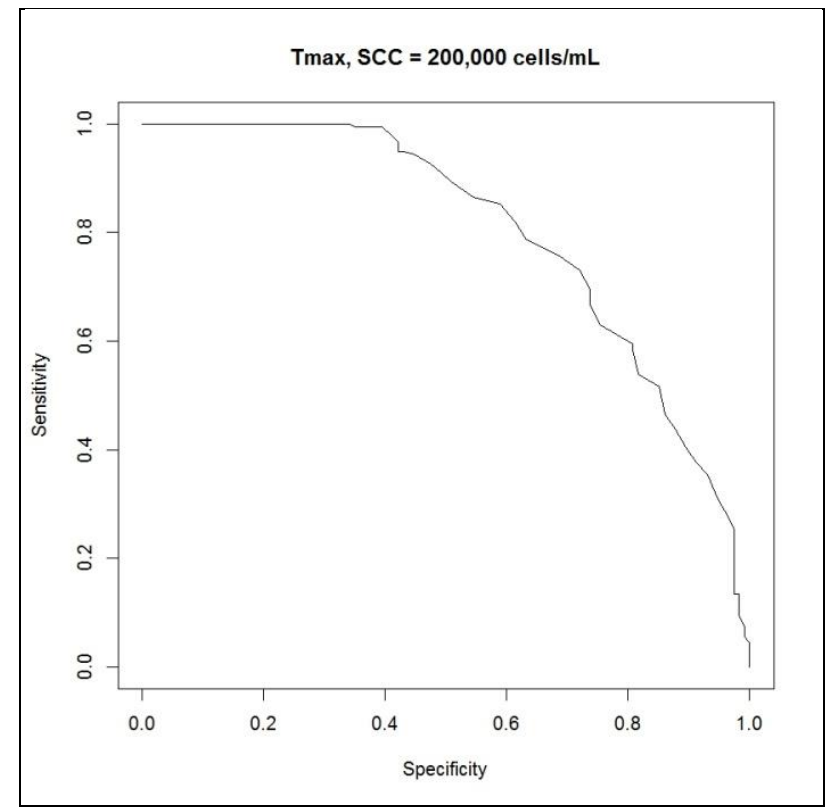

Fig. 2: ROC curve of the statistical test built evaluating the parameter $T_{\max }$ and different possible cutoff levels. For the determination of udder health status, an SSC' threshold of 200,000 cells/mL was used. The ROC curve was obtained through the procedures "prediction" and "performance", package "ROCR" of the "R" statistical software tool.

In a following phase the AUC and the final cutoff level were calculated for the ROC curve obtained. The final cutoff level was identified considering the point, in the curve, closer to the best theoretical result (i.e. the point in the graph in the upper right corner equal to a sensitivity and specificity of $100 \%$ ). Results obtained are reported in table 2 , while means and standards errors values of the main parameters investigated are shown in table 1.

Table 1. Descriptive statistics of the main parameters investigated (Tmax, SCC and APT) in terms of mean and standard error (S.E.) values for the criterion adopted to classified the udder health status (i.e. udder health = "healthy" if

\begin{tabular}{|c|c|c|c|c|c|}
\hline $\begin{array}{l}\text { SCC } \\
\text { Threshold } \\
\text { (cells } / \mathrm{mL} \text { ) }\end{array}$ & $\begin{array}{l}\text { Udder health state } \\
\text { (healthy/unhealthy) }\end{array}$ & $\begin{array}{l}\text { Cases } \\
\text { (n) }\end{array}$ & $\begin{array}{c}\mathrm{T}_{\max } \\
\left({ }^{\circ} \mathrm{C},\right. \\
\text { means } \pm \text { S.E. })\end{array}$ & $\begin{array}{c}\text { SCC } \\
\text { (x } 103 \text { cells } / \mathrm{mL}, \\
\text { means } \pm \text { S.E. })\end{array}$ & $\begin{array}{c}\text { APT } \\
\text { (\# pixels, } \\
\text { means } \pm \text { S.E.) }\end{array}$ \\
\hline
\end{tabular}
$S C C<$ of 200,000 cells $/ \mathrm{mL}$; udder health = "unhealthy" if SCC > of 200,000 cells $/ \mathrm{mL}$ ). 


\begin{tabular}{|c|l|c|c|c|c|}
\hline \multirow{2}{*}{200,000} & healthy & 114 & $34.38 \pm 0.13$ & $86.42 \pm 5.14$ & $10,164 \pm 654$ \\
\cline { 2 - 5 } & unhealthy & 178 & $35.86 \pm 0.07$ & $1,752.88 \pm 184.12$ & $5,702 \pm 378$ \\
\hline
\end{tabular}

Table 2. Final performance of the statistical test based on the evaluation of the parameter Tmax. In the table, AUC, sensitivity, specificity, and the corresponding cut-off level are reported for the SCC threshold used to classify udders health status. The values reported in the table were calculated through a customized function developed for the "R" statistical software tool.

\begin{tabular}{|c|c|c|c|c|}
\hline $\begin{array}{c}\text { SCC Threshold } \\
(\text { cells } / \mathrm{mL})\end{array}$ & $\begin{array}{c}\text { AUC } \\
(\text { Area })\end{array}$ & $\begin{array}{c}\text { Sensitivity } \\
(\%)\end{array}$ & $\begin{array}{c}\text { Specificity } \\
(\%)\end{array}$ & $\begin{array}{c}\text { Cutoff level } \\
\left({ }^{\circ} \mathrm{C}\right)\end{array}$ \\
\hline 200,000 & 0.801 & 73.0 & 71.9 & 35.4 \\
\hline
\end{tabular}

\section{Discussion}

In our study, the area of cow udder involved in a local increase of USST was investigated. In each thermographic image, the "temperature proximity area" (APT), calculated using the software algorithm developed for the specific elaboration of IRT images, has shown a relationship with the mean values of $T_{\max }$ (and of SCC). In detail, in case of unhealthy udder, mean values of $\mathrm{T}_{\max }$ (and levels of SSC) showed to increase and mean values of $\mathrm{AP}_{\mathrm{T}}$ showed to be lower. This result seems to suggest that cases of high USSTs should be coupled with small values of $A P_{T}$, according with a real local rise of temperature due to changes of underlying circulation and tissue metabolism [16] caused by the presence of a local inflammation of the mammary gland [8]. This parameter, therefore, could be useful to increase the detection performance of the parameter USST, evaluated using an IRT camera, since that commercial cameras can show reading errors up to $\pm 2{ }^{\circ} \mathrm{C}$. Even though most of them have an internal function to automatically perform a calibration, this effect could negatively affect the performance of a system for the automatic monitoring of udder health status based on the evaluation of the parameter $T_{\max }$ through an absolute threshold. Furthermore, individual differences of animals can always negatively affect the use of simple indicator (i.e. the $T_{\max }$ ) in a field application. Thus, a combined evaluation of $T_{\max }$ and APт, obtained thanks to the specific algorithm developed, could allow to overcome the issues above and reduce possible false positive cases, allowing the use of IRT for the automatic monitoring of udder health status in field conditions. Future studies will be useful to confirm this hypothesis.

In previous researches some authors have investigated which area of the cow udder should be more promising for the measurement of a correct and significant USST. For the measurement of the USST Porcionato et al. [17] used three areas selected considering the udder' height in the dorsal-ventral direction. Hovinen et al. [6] considered circles of dimensions $40 \times 40$ pixels positioned immediately above the teats from the lateral side of the cow udder reporting that the maximum temperature recordable on each udder not always was inside the area considered for the measurements. Metzner et al. [18], in order to limit possible mistakes due by personal interpretation of thermografic images, tried to define a standardized procedure based on the manual drawing of three different geometrical shapes on the rear side of each cow udder. The authors have remarked that an effective detection of mastitis, through an automatic monitoring system working in a milking parlour, could be reached only if the USST would be measured and analyzed in a standardized way. They suggested as main features of a possible algorithm: 1) an automatic identification of the udder shape based on the major temperatures of this area; 2 ) the elimination of the anatomical parts not useful to the measurement of USST; 3 ) the use of all possible pixels of the thermografic image in order to limit possible measurement mistakes due by dirty particles on udder skin and/or other possible imaging artefacts. In our study, an algorithm for the calculation of USST from thermographic images was developed in accordance with suggestions provided by Metzner et al. [18]. The algorithm allowed to automatically detect the correct udder area on the basis of the higher skin temperatures and to calculate the USST considering the maximum number of pixels of the thermografic image evaluated. This algorithm could run in real time and it could be easily integrated in a real monitoring system for the udder health status surveillance. Thus, it could be considered as a possible technical solution to the needs previously stated by these authors. Further experiments will be useful in order to test this technology solution in a real field application.

In this study, $\mathrm{T}_{\max }$ values were also investigated to discriminate possible unhealthy states of cow udder. Results obtained showed the detection accuracy of this parameter: a sensitivity of $73.0 \%$ and a specificity of $71.9 \%$ using as SSC' threshold a level of 200,000 cells $/ \mathrm{mL}$. Even though milk samples were not collected for each single udder quarter, this results seems to confirm what reported by other authors about the use of USST as a possible index for a rapid and noninvasive evaluation of udder health status [6-8]. Further tests will be useful to confirm this result and to reach an effective accuracy in the automatic and early detection of possible case of mastitis.

\section{Conclusions}

The USST evaluated by an infrared camera and the developed software algorithm, confirmed a possible relationship between the levels of SSC and the healthy states of cow udder. Futhermore, sensitivity and specificity found, considering a level of 200,000 cells $/ \mathrm{mL}$, remarked this result. Future experiments will be useful to improve the use of IRT 
and to define an automatic monitoring system based on the software algorithm and on the parameters tested in this first field investigation.

\section{REFERENCES}

[1] M. Zaninelli, L. Rossi, A. Costa, F. M. Tangorra, A. Agazzi, and G. Savoini, "Monitoring of goats' health status by on-line analysis of milk electrical conductivity | Monitoraggio dello stato di salute delle capre attraverso l'analisi online della conducibilità elettrica del latte," Large Anim. Rev., vol. 21, no. 2, pp. 81-86, 2015.

[2] C. M. Duarte, P. P. Freitas, and R. Bexiga, "Technological advances in bovine mastitis diagnosis: an overview," Journal of Veterinary Diagnostic Investigation, vol. 27, no. 6. pp. 665-672, 2015.

[3] M. Sathiyabarathi, S. Jeyakumar, A. Manimaran, G. Jayaprakash, H. A. Pushpadass, M. Sivaram, K. P. Ramesha, D. N. Das, M. A. Kataktalware, M. A. Prakash, and R. D. Kumar, "Infrared thermography: A potential noninvasive tool to monitor udder health status in dairy cows," Vet. World, vol. 9, no. 10, pp. 1075-1081, 2016.

[4] S. Pyörälä and S. Taponen, "Coagulase-negative staphylococci-emerging mastitis pathogens," Vet Microbiol, no. 134, pp. 3-8, 2009.

[5] M. Zaninelli, F. M. Tangorra, A. Costa, L. Rossi, V. Dell'Orto, and G. Savoini, "Improved fuzzy logic system to evaluate milk electrical conductivity signals from on-line sensors to monitor dairy goat mastitis," Sensors, vol. 16, no. 7, p. 1079, 2016.

[6] M. Hovinen, J. Siivonen, S. Taponen, L. Hänninen, M. Pastell, A. Aisla, and S. Pyörälä, "Detection of Clinical Mastitis with the Help of a Thermal Camera," J. Dairy Sci., vol. 91, no. 12, pp. 4592-4598, 2008.

[7] B. Polat, A. Colak, M. Cengiz, L. E. Yanmaz, H. Oral, A. Bastan, S. Kaya, and A. Hayirli, "Sensitivity and specificity of infrared thermography in detection of subclinical mastitis in dairy cows," J. Dairy Sci., vol. 93, no. 8, pp. 35253532, 2010.

[8] A. Colak, B. Polat, Z. Okumus, M. Kaya, L. E. Yanmaz, and A. Hayirli, "Short Communication: early detection of mastitis using infrared thermography in dairy cows," J. Dairy Sci., vol. 91, no. 11, pp. 4244-4248, 2008.

[9] A. Bortolami, E. Fiore, M. Gianesella, M. Corrò, S. Catania, and M. Morgante, "Evaluation of the udder health status in subclinical mastitis affected dairy cows through bacteriological culture, Somatic Cell Count and thermographic imaging," Pol. J. Vet. Sci., vol. 18, no. 4, pp. 799-805, 2015.

[10] S. L. Scott, A. L. Schaefer, A. K. W. Tong, and P. Lacasse, "Use of infrared thermography for early detection of mastitis in cows," in Agri-Food 2000, 2000.

[11] M. Metzner, C. Sauter-Louis, A. Seemueller, W. Petzl, and H. Zerbe, "Infrared thermography of the udder after experimentally induced Escherichia coli mastitis in cows," Vet. J., vol. 204, no. 3, pp. 360-362, 2015.

[12] NMC., Laboratory and Field Hand-book on Bovine Mastitis, 3th ed. Arlington, VA, USA: National Mastitis Council Inc., 2017.

[13] V. Poikalainen, J. Praks, I. Veermäe, and E. Kokin, "Infrared temperature patterns of cow's body as an indicator for health control at precision cattle farming," Agron. Res., vol. 10, no. SPEC. ISS. 1, pp. 187-194, 2012.

[14] M. Zaninelli, V. Redaelli, E. Tirloni, C. Bernardi, V. Dell'Orto, and G. Savoini, "First results of a detection sensor for the monitoring of laying hens reared in a commercial organic egg production farm based on the use of infrared technology," Sensors, vol. 16, no. 10, pp. 1-13, 2016.

[15] Team R Core Development, $R: A$ language and environment for statistical computing. Vienna, Austria: $\mathrm{R}$ Foundation for Statistical Computing, 2008.

[16] R. J. Berry, A. D. Kennedy, S. L. Scott, B. L. Kyle, and A. L. Schaefer, "Daily variation in the udder surface temperature of dairy cows measured by infrared thermography: Potential for mastitis detection," Can. J. Anim. Sci., vol. 83, no. 4, pp. 687-693, 2003.

[17] M. A. F. Porcionato, T. F. Canata, C. E. L. De Oliveira, and M. V. Dos Santos, "Udder Thermography of Gyr Cows for Subclinical Mastitis Detection / Termografia Do Úbere De Vacas Gir Para Detecção De Mastite Subclínica," Rev. Bras. Eng. Biossistemas, vol. 3, no. 3, p. 251, 2009.

[18] M. Metzner, C. Sauter-Louis, A. Seemueller, W. Petzl, and W. Klee, "Infrared thermography of the udder surface of dairy cattle: Characteristics, methods, and correlation with rectal temperature," Vet. J., vol. 199, no. 1, pp. 5762, 2014. 